\title{
Role of soil moisture-atmosphere feedback during high temperature events in 2002 over Northeast Eurasia
}

\author{
Enkhbat Erdenebat (i) and Tomonori Sato
}

\begin{abstract}
In summer 2002, abnormally high-temperature events and associated low soil moisture conditions were observed in Northeast Eurasia. In this study, two regional climate model experiments, one with and the other without soil moisture-atmosphere interaction, were conducted to investigate the role of soil moisture in surface air temperature and precipitation in Northeast Eurasia utilizing the Weather Research and Forecasting (WRF) model. In the experiment without interaction, satellite-based soil moisture was prescribed. Under the persistent mid-tropospheric ridge pattern with prolonged clear skies, both experiments captured the magnitude of the extreme surface air temperature events. A comparison of the model experiments demonstrated that the mid-tropospheric ridge pattern was intensified by dry soil moisture conditions that further increase the surface air temperature. The temporal variability of surface air temperature for the experiments with and without soil moisture-atmosphere interaction reveals the strong coupling of soil moisture to surface air temperature in June-August, raising the possibility that extreme hot temperature events in Northeast Eurasia were strengthened by the soil moisture anomaly. These results also indicate that the impact of soil moisture-atmosphere coupling on surface air temperature varies spatially and temporally, having higher importance for the predictability of extreme high-temperature events in Northeast Eurasia during mid-summer. This also suggests that the performance of the land surface model in simulating appropriate land-atmosphere coupling intensity is a key to evaluating the impact of climate change on extreme heat events in this region.
\end{abstract}

Keywords: Extreme temperature, Soil moisture, Land-atmosphere interaction, Northeast Eurasia

\section{Introduction}

The global mean surface air temperature (SAT) has been increasing steadily since the middle of the 1950s (Hartmann et al. 2013). It is widely known that the spatiotemporal variation in mean and extreme temperature increase is not uniform. Thus, several hot spots where warming rate is greater than the surrounding areas have been identified across the world (Alexander et al. 2006; Della-Marta et al. 2007; Seneviratne et al. 2012). In America, Europe, Australia, and Asia, the number of extreme-temperature-related weather events has increased as mean SAT has increased since 1950 (Seneviratne et al. 2012). Record-breaking extreme high-temperature events that occurred recently in Europe and North America have focused attention on the

\footnotetext{
* Correspondence: enkhbat@ees.hokudai.ac.jp

Graduate School of Environmental Science, Hokkaido University, Kita-10, Nishi-5, Sapporo 060-0810, Japan
}

(c) The Author(s). 2018 Open Access This article is distributed under the terms of the Creative Commons Attribution 4.0 International License (http://creativecommons.org/licenses/by/4.0/), which permits unrestricted use, distribution, and reproduction in any medium, provided you give appropriate credit to the original author(s) and the source, provide a link to the Creative Commons license, and indicate if changes were made.

interannual variation in extreme high-temperature events and the physical mechanisms responsible for them, such as atmospheric circulation and the possible contribution of the land surface (Black et al. 2004; Meehl and Tebaldi 2004; Schär et al. 2004; Ferranti and Viterbo 2006; Fischer et al. 2007; Lau and Nath 2012).

A persistent anticyclonic circulation and blocking are the important atmospheric forcing conditions that cause hot weather events such as heat waves (HWs) in the mid-latitude regions (Dole et al. 2011; Schubert et al. 2014). In the 2000s, the mid-tropospheric ridge pattern was dominant during June-July-August (JJA) in Northeast Eurasia, providing favorable conditions for HWs (Erdenebat and Sato 2016). Soil moisture (SM) in JJA had declined in this region due to the lack of precipitation, and this possibly intensified the land-atmosphere interaction (Erdenebat and Sato 2016).

\section{SpringerOpen}


Water availability in the soil regulates evapotranspiration that alters air temperature and humidity in the lower atmosphere. Pre-existing dry soil conditions enhance surface sensible heat flux and limit evapotranspiration, leading to a rapid increase of SAT (Zaitchik et al. 2006). Observations and reanalysis data suggested a possible contribution of SM to the recent increasing number of HWs (Beniston 2004; Weisheimer et al. 2011; Erdenebat and Sato 2016). However, analysis of observations and reanalysis data has limitations for examining the role of SM in HWs because it is difficult to distinguish SM-to-HW and HW-to-SM contributions as both processes occur simultaneously during the hot events.

Several numerical studies have been conducted to determine the importance of SM conditions on precipitation variability (Koster et al. 2004; Su and Dickinson 2017) and HWs (Fischer et al. 2007; Seneviratne et al. 2006). The SM deficit was found to have a role in intensifying the European HW in 2003 (e.g., Fischer et al. 2007). Fischer et al. (2007) concluded that the warm summer temperature anomalies in 2003 would have been reduced by $40 \%$ if the SM had been at the level of the climatological mean. In North America, the SM anomaly in April tends to persist until July as a result of local positive feedback processes between SM and the atmosphere, as the surface heat flux anomaly in July induces a wave pattern in the upper troposphere (Koster et al. 2014). This suggests the influence of SM-atmosphere interaction on the predictability of hot events. Berg et al. (2015) found that the co-variability of temperature and precipitation is controlled by SM through surface heat flux partitioning. Thus, a reliable hydrological cycle in the model may reduce uncertainty in future projections. Although the effect of global SM-atmosphere interactions on the intensity of severe HWs has been studied, HW events in Northeast Eurasia have not been studied intensively, especially from the viewpoint of SM-atmosphere interaction during a hot summer.

Summer 2002 was the hottest summer in Northeast Eurasia over the period 1981-2010. In Mongolia, the accumulated summer duration of the strong mid-tropospheric ridge in 2002 was the longest over the period 1981-2010 (Erdenebat and Sato 2016). In addition, the SM averaged over $42^{\circ} \mathrm{N}-52^{\circ} \mathrm{N}, 90^{\circ} \mathrm{E}-120^{\circ} \mathrm{E}$ (black box in Fig. 1a) derived from ERA-Interim at surface layer $(0-7 \mathrm{~cm}$ depth) was $0.213,0.215$, and $0.205 \mathrm{~m}^{3} \mathrm{~m}^{-3}$ for June, July, and $\mathrm{Au}-$ gust 2002, respectively, lower than the JJA mean SM for 1981-2010 $\left(0.223 \mathrm{~m}^{3} \mathrm{~m}^{-3}\right)$. The significantly low SM in 2002 may have played a role in further intensifying HWs. In Mongolia, the SM affects the predictability of interannual variation in precipitation (Sato and Xue 2013). However, the contribution of SM to HW in Northeast Eurasia is not known. Therefore, this study aims to investigate the role of SM-atmosphere interactions during extreme HW events in summer 2002 over Northeast Eurasia.

\section{Methods/Experimental}

Data

ERA-Interim (Dee et al. 2011) reanalysis data at $0.75^{\circ} \times$ $0.75^{\circ}$ resolution from the European Centre for Medium-range Weather Forecasts (ECMWF) were used to examine atmospheric circulation, geopotential height, SM, and temperature variations from June to August 2002. The ERA-Interim has been shown to be the most reliable reanalysis dataset in terms of extreme temperature variation (Gross et al. 2017). ERA-Interim data were used as initial and boundary conditions for the regional model experiments and to validate the model results over a large area. For SM validation and analysis, the shallowest level (0-7 cm depth) of ERA-Interim data was used at time intervals of 1 day. Daily maximum SAT and precipitation at 70 meteorological stations in Mongolia provided by the National Agency for Meteorology and Environment Monitoring of Mongolia were also used. Daily gridded precipitation data from Asian Precipitation Highly Resolved Observational Data Integration Towards Evaluation (APHRODITE; Yatagai et al. 2012) were used to evaluate precipitation variation. Anomalies in observations and reanalysis data are calculated with respect to the corresponding 30-year (1981-2010) mean. We used the European Space Agency-Climate Change Initiative (ESA-CCI; Liu et al. 2011) version 2.2 multi-satellite SM product as an initial SM condition for model experiments and to constrain the SM in the model. This SM product has a spatial resolution of $0.25^{\circ} \times 0.25^{\circ}$ and represents the volumetric soil water content $\left(\mathrm{m}^{3} \mathrm{~m}^{-3}\right)$ in the uppermost $10 \mathrm{~cm}$ of the soil layer.

\section{Model setup}

To evaluate the role of SM in HW events, numerical experiments were conducted with the non-hydrostatic Weather Research and Forecasting (WRF) model version 3.6 (Skamarock et al. 2005) using the Advanced Research WRF (ARW) solver. The physics schemes are mostly as in Sato and Xue (2013), who assessed the model performance over Northeast Eurasia: the Eta (Ferrier) microphysics scheme (Rogers et al. 2001), the Kain-Fritsch cumulus parameterization scheme (Kain 2004), the rapid radiative transfer model longwave radiation scheme (Mlawer et al. 1997), the Dudhia shortwave radiation scheme (Dudhia 1989), and the Unified Noah land-surface model (LSM; Ek et al. 2003). The Noah LSM considers four layers in the ground (10, 30, 60, and $100 \mathrm{~cm}$ depth below the ground surface). The model domain has $340 \times 260$ grid points with a resolution of $20 \mathrm{~km}$ covering most of Northeast Eurasia centered around Mongolia (Fig. 1a). Initial and boundary conditions are obtained from ERA-Interim data (Dee et al. 2011) at 6-hour intervals. To consider the nonlinear atmospheric response to SM, we conducted five ensemble experiments with slightly different initial dates starting at 0000 UTC on 13, 14, 15, 16, and 17 June 2002. 


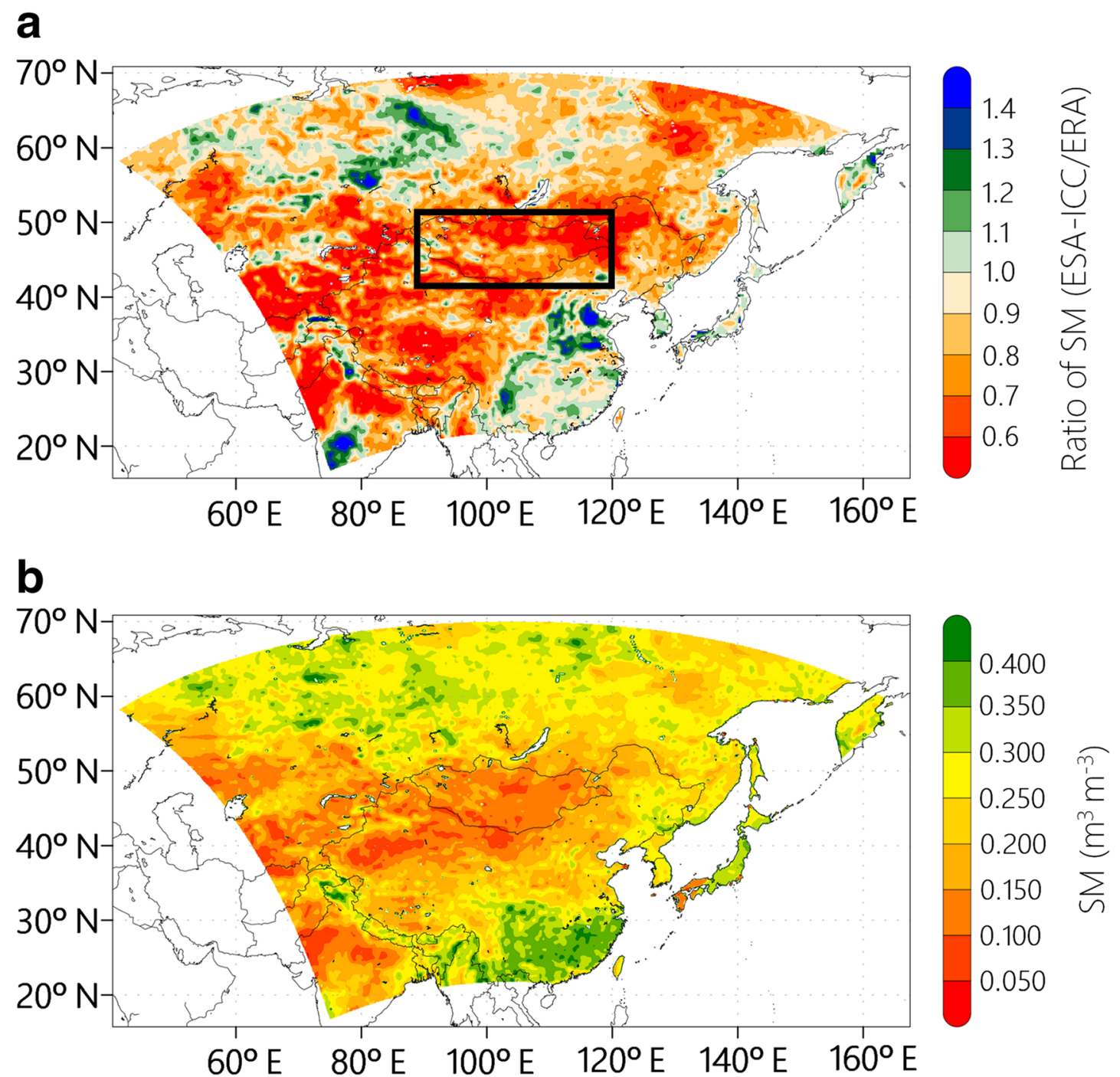

Fig. 1 a Domain of the numerical experiment. Color shading represents the SM ratio between ESA-CCI and ERA-Interim (ESA-CCI divided by ERAInterim) for the surface layer during 11-20 June 2002. The black box presents the sub-domain used for area averaging. b Initial SM condition $\left(\mathrm{m}^{3} \mathrm{~m}^{-3}\right)$ at 0-10 $\mathrm{cm}$ for the WRF experiment initialized at 0000 UTC 13 June 2002

All experiments ended at 0000 UTC on 1 September 2002. The ensemble-mean model output between 20 June and 31 August 2002 (referred to as JJA in the model analysis) is used in the analysis unless indicated otherwise.

\section{Experimental design}

To evaluate the impact of SM on HW, two numerical experiments were conducted, one with and one without $\mathrm{SM}$-atmosphere interaction. In the experiment with SM-atmosphere interaction, SM varies according to the hydrological cycle simulated by two-way coupling between land and atmospheric processes (hereinafter, the CSM experiment). In the experiment without SMatmosphere interaction (hereinafter, the PSM experiment), SM was prescribed using the original SM dataset as described below and thus varies independently of the atmospheric conditions.

To obtain a realistic spatial distribution of initial SM for both experiments in 2002, we created a new SM dataset based on ERA-Interim after applying a bias correction using the ESA-CCI satellite-based product. Firstly, the climatological mean (1981-2010) field of SM was created from the ESA-CCI for the period 11-20 June to use as a reference field to fill missing grid points. Then, pentad interval SM was created using ESA-CCI during 11-20 June 2002. To interpolate the missing grid points, we applied a ratio of pentad climatological SM between the missing grid point and available neighboring grid points onto the pentad SM field in 2002. Secondly, pentad interval SM data were created using the ERA-Interim in the 
same period for each layer. We calculated the ratio of ESA-CCI (0-10 cm depth) to ERA-Interim (shallowest level, 0-7 cm) SM defined for each pentad during 11-20 June 2002 (Fig. 1a). The ratio below 1.0 indicates that ERA-Interim SM is wetter than ESA-CCI SM. Although there is a small difference in the thickness of the layer in each case, we consider that both datasets reflect surface SM conditions. Then, the ratio was multiplied by the ERA-Interim SM time series in four layers $(0-7,7-28$, $28-100,100-255 \mathrm{~cm})$, assuming that the ratio is the same for all layers. Finally, SM in the four soil layers $(0-10,10$ $40,40-100,100-200 \mathrm{~cm}$ ) of the Noah LSM was obtained by linear interpolation (Fig. 1b). In the following analysis, we used the SM in the $0-10 \mathrm{~cm}$ depth layer. In the PSM experiment, the SM of all ground layers was prescribed at hourly intervals. To create hourly SM data, we prepared pentad SM fields from 11 June to 1 September 2002 as described above for the SM fields for initial conditions. Then, the pentad SM was linearly interpolated to the hourly interval. The same initial condition of SM was used for the CSM and PSM experiments if their initialization dates are the same. Each ensemble member uses different initial SM since they are initialized at different date.

In the PSM experiment, the variation in SM is independent of the precipitation predicted in the WRF model. By comparing the CSM and PSM experiments, we will discuss the impact of SM-atmosphere interaction on HW events in summer 2002.

\section{Results and discussion}

Atmospheric circulation and observed temperature in JJA 2002

In this study, the occurrence of HW was judged for each day and for each station in summer 2002 based on the definition of Erdenebat and Sato (2016) which is summarized as follows. A HW was assigned if the daily maximum temperature exceeded the 30-year average (1981-2010) of daily maximum temperature by $5{ }^{\circ} \mathrm{C}$, and remained at this level for at least four

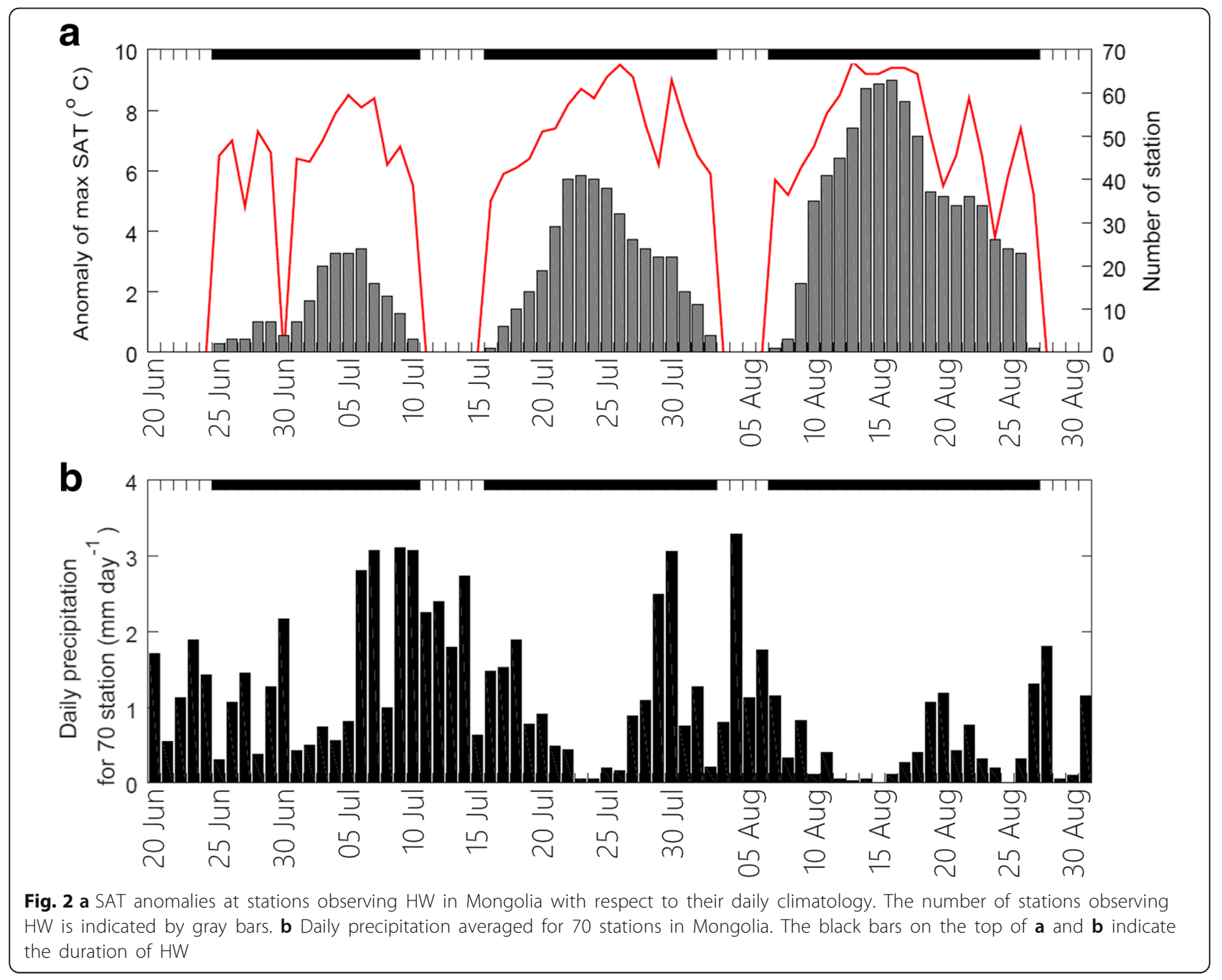


consecutive days. Events with a 1-day interruption were also regarded as HW.

In Mongolia, there were three distinct HW events in summer 2002. The average daily maximum SAT anomaly for stations with HW relative to the 30-year average of each calendar day remained high (Fig. 2a). In 2002, the number of stations experiencing a HW increased toward the end of summer, suggesting that the HW spread over a wider area (Fig. 2a). Summer of 2002 (JJA) was the driest summer during 1981-2010 in Mongolia (Erdenebat and Sato 2016). The daily precipitation in JJA 2002 has decreased gradually toward the end of the summer in Mongolia (Fig. 2b). In general, an anomalous planetary wave is a key factor in triggering abnormal SAT events in the mid-latitudes (e.g., Black et al. 2004; Meehl and Tebaldi 2004). The mid-tropospheric atmospheric circulation was investigated during JJA of 2002 using reanalysis datasets. Figure 3a shows the SAT and $500 \mathrm{hPa}$ wind and geopotential height anomalies in JJA of 2002 relative to the climatology. Note that SAT is examined at 0600 UTC (1400 LT) and all the other parameters are daily means. In the JJA mean wind field at $500 \mathrm{hPa}$ geopotential height, a weak southwesterly over Northeast Europe and Northeast Asia and a northwesterly over the west Siberian plain were apparent, corresponding to positive and negative geopotential height anomalies, respectively. There was a pair of positive anomalies in geopotential height over Northeast Europe and Asia, corresponding to regions with warm SAT. The anomalous geopotential height in JJA 2002 was very similar to the decadal mean for 2001-2010 when many intense HWs occurred (Erdenebat and Sato 2016). This suggests that the summer of 2002 is a characteristic period representing recent hot summers around the study area.

There occurred three massive HW events during summer 2002: from 25 June to 10 July, from 16 July to 02 August, and from 07 August to 27 August (hereafter, the first, second, and third HW events, respectively). The first

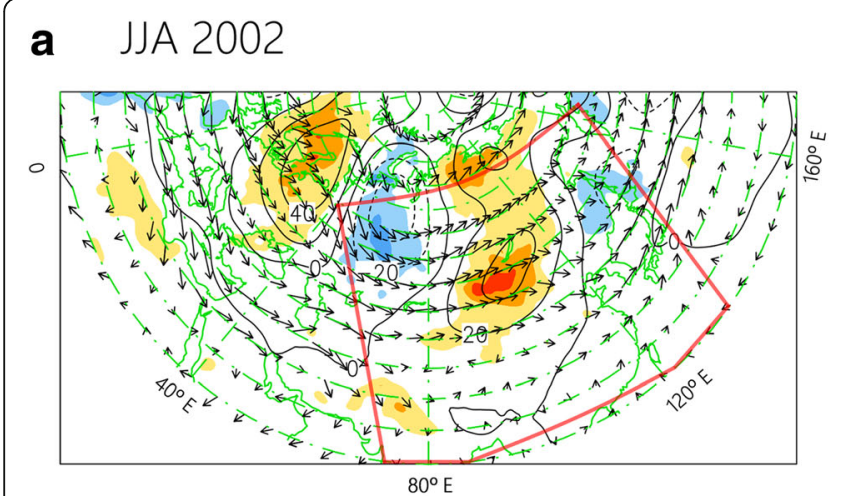

\section{b 1st HW (25Jun-10Jul)}

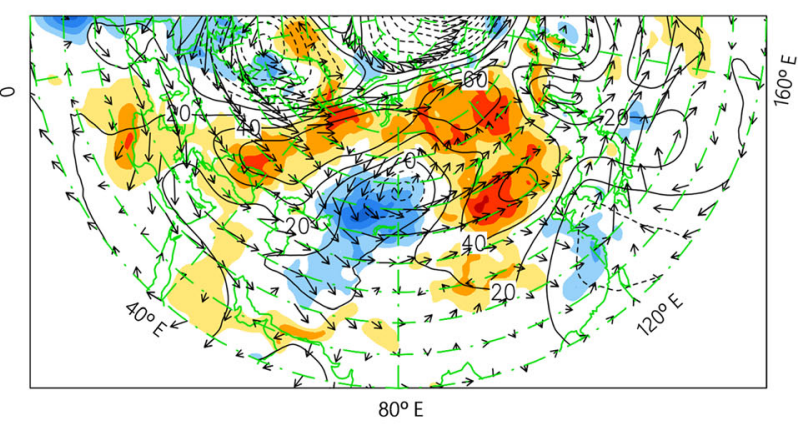

\section{c 2nd HW (16Jul-02Aug)}

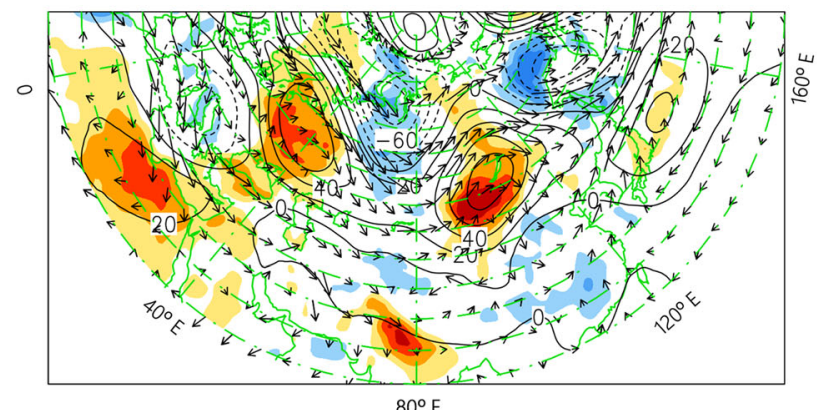

\section{d 3 rd HW (07Aug-27Aug)}
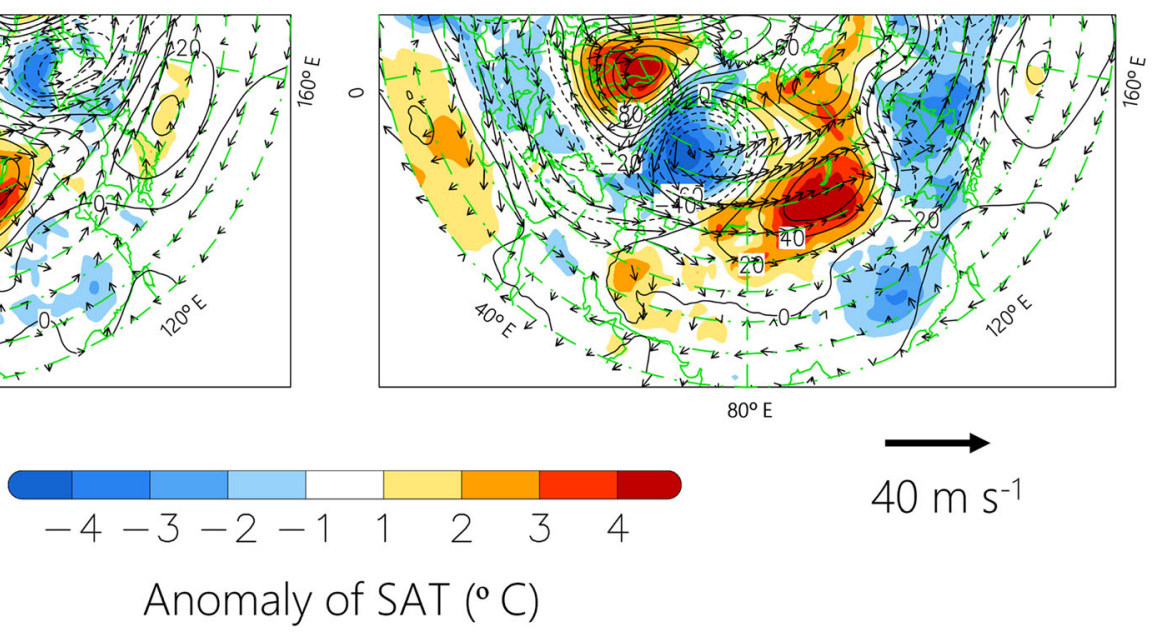

$40 \mathrm{~m} \mathrm{~s}^{-1}$

\section{Anomaly of SAT $\left({ }^{\circ} \mathrm{C}\right)$}

Fig. 3 Distribution of SAT ( ${ }^{\circ} \mathrm{C}$, shaded), geopotential height ( $\mathrm{m}$, contours), and wind ( $\mathrm{m} \mathrm{s}^{-1}$, arrows) at $500 \mathrm{hPa}$, in a JJA 2002 , b first HW (25 June to 10 July), c second HW (16 July to 2 August), and $\mathbf{d}$ third HW (7 August to 27 August). Variables in $\mathbf{b}$-d are expressed as anomalies with respect to the 30-year average (1981-2010) of the corresponding period, but as the mean absolute value for wind at the $500 \mathrm{hPa}$ level. The red line in a delineates the study domain by model. Negative contours are shown by dashed lines 
HW event in late June (Fig. 3b) had a different wave propagation pattern from the subsequent two events (Fig. 3c, d). Figure 3b shows a positive anomaly of $500 \mathrm{hPa}$ geopotential height over Northeast Eurasia associated with a negative anomaly over Scandinavia and the west Siberian plain. In the second $\mathrm{HW}$, the height anomaly during mid-July to early August was highest $(+80 \mathrm{~m})$ over Mongolia. Similarly, high positive anomalies $(+60 \mathrm{~m})$ were observed for the first and third HW in Mongolia. The third HW event (7-27 August) had the largest spatial extent. The persistent positive anomalous field at $500 \mathrm{hPa}$ geopotential height suggests that the prevailing ridge pattern in Northeast Eurasia was associated with the atmospheric circulation in regions upstream of the dominant westerly winds. For aforementioned three events, the mid-latitude wave trains seem to be a main trigger of HWs over Northeast Eurasia although each event has slightly different wave propagation patterns.

To clarify the local intensification of HWs and the origin of the warm air, a Hovmöller diagram of SAT is depicted for the meridional average between $42^{\circ} \mathrm{N}$ and $52^{\circ} \mathrm{N}$ (Fig. 4a). There are two regions of anomalously high SAT: Europe around $40^{\circ} \mathrm{E}-60^{\circ} \mathrm{E}$ and East Asia around $90^{\circ} \mathrm{E}-$ $120^{\circ} \mathrm{E}$. The warm SAT anomaly relative to the 30 -year daily mean (1981-2010) propagating from Europe to Asia was weak in early summer (1 June to 15 July 2002). This weak SAT anomaly before the first HW event is due to its different wave propagation pathway at $500 \mathrm{hPa}$ (Fig. 3b) which is not captured by the Hovmöller diagram. There was a cold anomaly of daily SAT $\left(-2.2^{\circ} \mathrm{C}\right.$, averaged over 1 June to 15 July 2002) between $60^{\circ} \mathrm{E}$ and $80^{\circ} \mathrm{E}$ (Fig. 4b), but this tended to weaken toward the end of summer. There was eastward propagation of SAT anomalies from Europe to Asia as indicated by the mean warm anomaly of $0.4^{\circ} \mathrm{C}$ over $60^{\circ} \mathrm{E}-80^{\circ}$ E from 16 July to 31 August 2002 (Fig. 4b). Eastward propagation of the warm SAT anomaly is intensified around Northeast Eurasia between $90^{\circ} \mathrm{E}$ and $120^{\circ} \mathrm{E}$.

The temporal variations in local SAT and SM were investigated over Mongolia (Fig. 4c). There is a pronounced negative relationship between SM and SAT. The correlation coefficients between daily mean SM and SAT from ERA-Interim (at $1400 \mathrm{LT}$ ) averaged around Mongolia (black box in Fig. 1a) were $-0.632,-0.634$, and -0.625 for June, July, and August, respectively. The correlation coefficients are enhanced during HW periods, with values of $-0.872,-0.885$, and -0.836 for the

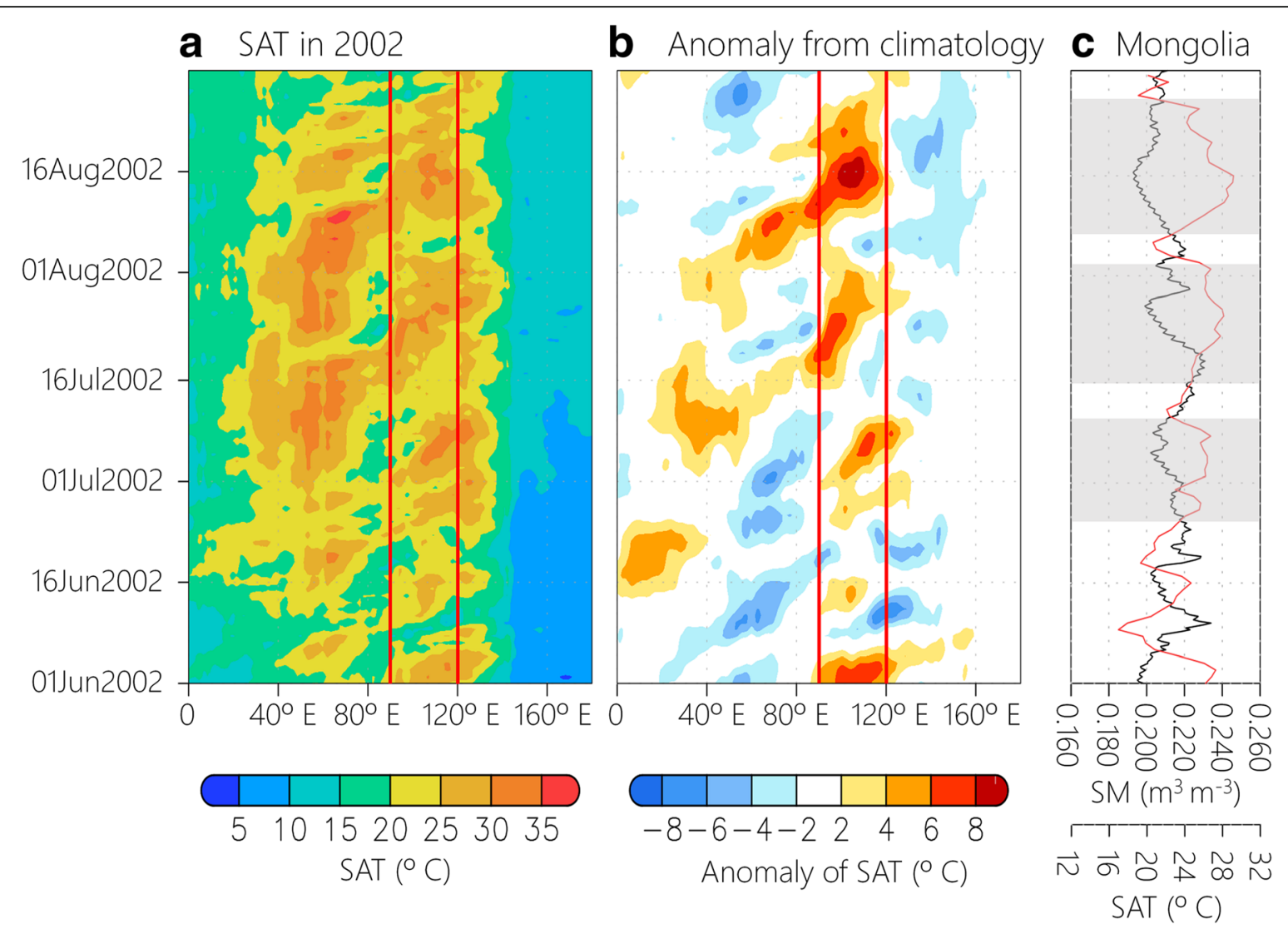

Fig. 4 The Hovmöller diagram (averaged between $42^{\circ} \mathrm{N}$ and $52^{\circ} \mathrm{N}$ ) of a SAT in 2002 summer and $\mathbf{b}$ its anomaly from the 30-year mean daily SAT in ERA-Interim. c Time series of SAT (red line) and SM (black line) in ERA-Interim averaged over Mongolia (black box in Fig. 1a). Red straight lines in $\mathbf{a}$ and $\mathbf{b}$ represent Mongolia. The gray shadings in $\mathbf{c}$ represent the durations of HW events 
first (25 June to 10 July), second (16 July to 2 August), and third (7 to 27 August) HW events, respectively. The high negative correlation (95\% significance) during HW periods strongly suggests that SM-SAT interaction was crucial during the HW events. In the following section, the relationship between SM and HW events is investigated by numerical experiment to elucidate the role of land-atmosphere interaction.

\section{Experiment on SM-atmosphere interaction}

WRF experiments were conducted to examine the role of SM-atmosphere interaction during the HW event in 2002. The ensemble mean SM $(0-10 \mathrm{~cm}$ depth) variations averaged around Mongolia (black box in Fig. 1a) in the CSM and PSM experiments are shown in Fig. 5a. There is a gap in SM between the CSM and PSM throughout the summer. Although the CSM and PSM have the same initial SM, the CSM gets wetter during the spin up duration. As indicated by the wetter SM in ERA-interim than the satellite SM (Fig. 1a), it is reasonable to speculate that hydrological cycle in ERA-interim may be stronger than the real atmosphere, and thereby, our WRF experiments have weak biases in precipitation and SM (Table 1), allowing the SM gap between two experiments throughout the summer (Fig. 5a). The fluctuations of SM are larger in the CSM than in the PSM. The Hovmöller diagram of simulated SAT (at 1400 LT) averaged between $42^{\circ} \mathrm{N}$ and $52^{\circ} \mathrm{N}$ is depicted in Figs. $5 \mathrm{~b}, \mathrm{~d}$ to evaluate the performance of the CSM and PSM experiments in simulating zonal and temporal SAT variations.
Most of the cold and warm biases appear between $90^{\circ} \mathrm{E}$ and $120^{\circ} \mathrm{E}$. Figure $5 \mathrm{c}$, e shows the area-averaged deviation of SAT in the CSM and PSM with respect to ERA-Interim, respectively. The JJA SAT variation in the PSM experiment is statistically different $(p=0.10)$ from ERA-Interim, whereas that in the CSM experiment is not. On a subseasonal timescale, the CSM and PSM experiments underestimate SAT compared with ERA-Interim, especially during late July and August. The CSM experiment underestimates the JJA mean SAT by $0.6{ }^{\circ} \mathrm{C}$, with a root mean square error (RMSE) of daily SAT for JJA of $1.9^{\circ} \mathrm{C}$. In the PSM experiment, the mean bias and RMSE are -0.7 and $2.0^{\circ} \mathrm{C}$ for JJA, respectively. In both experiments, in comparison with ERA-Interim, the RMSE of area-averaged SAT around Mongolia was low for the first and second HWs, i.e., 1.4 and $1.2{ }^{\circ} \mathrm{C}$ in the CSM and 1.5 and $1.6^{\circ} \mathrm{C}$ in the PSM, respectively. In the first HW, SATs of the CSM and PSM experiments are not significantly different from ERA-Interim, which indicates that the model agrees well with reanalysis data. During the second HW, temporal- and area-averaged SAT in the CSM is close to ERA-Interim, whereas PSM underestimates SAT by $0.93{ }^{\circ} \mathrm{C}(p=0.10)$. The RMSE of SAT is highest in the third HW (7-27 August), with $1.9{ }^{\circ} \mathrm{C}$ in the CSM $(p=0.05)$ and $2.4{ }^{\circ} \mathrm{C}$ in PSM $(p=0.01)$. Those worsening of the SAT estimations in the PSM experiment confirm the importance of correct SM variation to SAT prediction in the model. Further analysis is carried out how SM impact on the heat flux partitioning among the experiments.

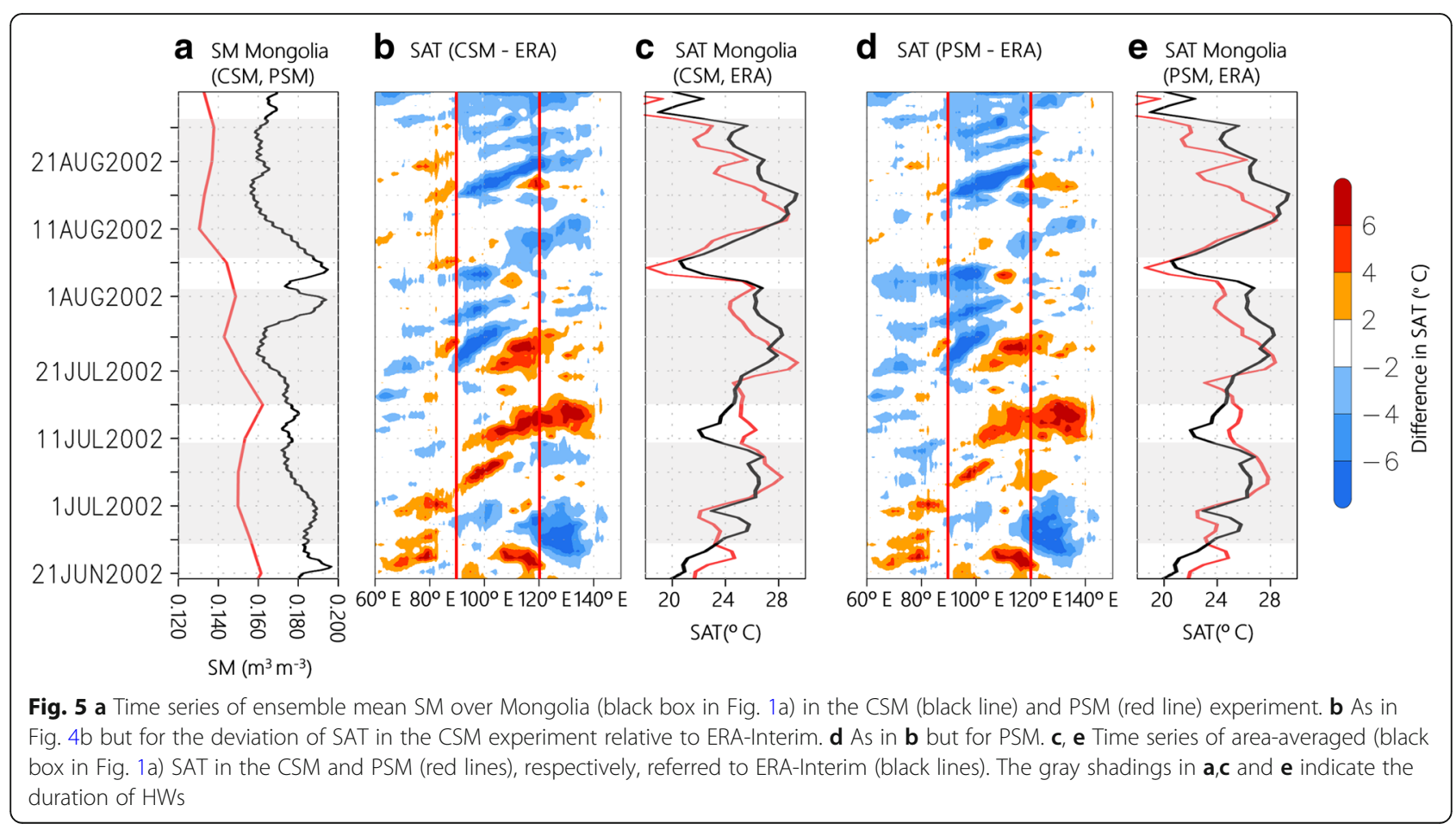


Table 1 lists the area-averaged (box in Fig. 1a) surface variables for the CSM, PSM, and reference datasets of ERA-Interim. Note that heat fluxes, SAT, and radiation are examined at 0600 UTC (1400 LT). As mentioned above, the SATs in the two experiments are similar to ERA-Interim, with the highest SAT during the second HW. Although the event-to-event changes of surface variables in WRF experiments are similar with ERA-Interim, some differences are present. The JJA-mean SM is pronouncedly wetter in ERA-Interim than the WRF model. Thus, in the WRF runs, less latent heat and more sensible heat fluxes are found in comparison to ERA-Interim. In particular, sensible heat flux in the WRF runs is much larger than that in ERA-Interim. Since simulated SM in the CSM is more tightly constrained by ERA-Interim fields than in PSM, the CSM shows greater precipitation and SM than the PSM. As a result, the latent (sensible) heat flux in PSM is smaller (larger) than in the CSM for the JJA-mean and also for each HW. The downward shortwave radiation during first and second HWs is far exceeding the JJA average, indicating less cloud cover, while it is relatively low in third HW because of the seasonal cycle of solar radiation. The downward radiations in CSM and PSM are comparable which suggests SM's influence on cloud cover is negligible for the JJA average although CSM tends to have larger downward radiation during HW events. Since the analysis was limited to the particular region and for three HW events, spatial distribution of the WRF's skill and its sensitivity to SM for simulating sub-seasonal SAT and precipitation variations were investigated as follows.

To investigate the impact of SM-atmosphere interaction on the geographical distribution of subseasonal variation, the temporal correlations of pentad mean time series between simulated and observed variables (SAT and precipitation) are shown in Fig. 6. In both the CSM and PSM experiments, a high correlation of SAT is obtained near the northern and western lateral boundaries where the atmosphere is less influenced by land surface conditions (Fig. 6a, c). The correlation of SAT deteriorates toward the center of the study domain, with the lowest correlation around southern China and the Far Eastern region of Russia. The southeastward decreasing tendency of the correlation coefficient of SAT suggests that the dependence of SAT on land surface conditions increases southeastward. The CSM outperforms the PSM for most of the center of the study domain (Fig. 6e), which means land-atmosphere interaction improves the temporal variation in SAT for continental regions where land surface processes play a crucial role in influencing SAT. On the other hand, the correlation was higher in the PSM than the CSM around the east coast of China. This suggests that having the correct SM in the PSM is more important than having SM-atmosphere interaction for the subseasonal variation in SAT in this area.

Table 1 Area-averaged (see Fig. 1a) mean surface variables in the CSM and PSM experiments and ERA-interim for corresponded periods. Note that heat fluxes, surface air temperature, and radiation are examined at 0600 UTC (1400 LT)

\begin{tabular}{|c|c|c|c|c|c|}
\hline & & $J J A$ & 1st HW & 2nd HW & 3rd HW \\
\hline \multirow[t]{3}{*}{ Surface air temperature $\left({ }^{\circ} \mathrm{C}\right)$} & CSM & 24.4 & 25.2 & 26.1 & 24.5 \\
\hline & PSM & 24.2 & 25.3 & 25.5 & 24.2 \\
\hline & ERA-interim & 25.0 & 25.3 & 26.4 & 26.2 \\
\hline \multirow[t]{3}{*}{ Soil moisture $\left(\mathrm{m}^{3} \mathrm{~m}^{-3}\right)$} & CSM & 0.173 & 0.180 & 0.172 & 0.164 \\
\hline & PSM & 0.146 & 0.152 & 0.150 & 0.135 \\
\hline & ERA-interim & 0.210 & 0.211 & 0.215 & 0.201 \\
\hline \multirow[t]{3}{*}{ Latent heat $\left(\mathrm{W} \mathrm{m}^{-2}\right)$} & CSM & 128.6 & 140.3 & 140.3 & 117.0 \\
\hline & PSM & 126.7 & 131.9 & 138.8 & 119.8 \\
\hline & ERA-interim & 141.2 & 152.6 & 162.9 & 128.0 \\
\hline \multirow[t]{3}{*}{ Sensible heat $\left(\mathrm{W} \mathrm{m}^{-2}\right)$} & CSM & 245.7 & 257.7 & 248.1 & 230.3 \\
\hline & PSM & 255.0 & 270.5 & 252.7 & 236.0 \\
\hline & ERA-interim & 193.5 & 200.6 & 188.1 & 189.6 \\
\hline \multirow[t]{3}{*}{ Precipitation $\left(\mathrm{mm}\right.$ day $^{-1}$ ) } & CSM & 1.4 & 1.6 & 1.6 & 0.7 \\
\hline & PSM & 1.3 & 1.4 & 1.4 & 0.8 \\
\hline & APHRODITE & 1.1 & 1.3 & 1.1 & 0.5 \\
\hline \multirow[t]{3}{*}{ Downward shortwave radiation $\left(\mathrm{W} \mathrm{m}^{-2}\right)$} & CSM & 823.7 & 871.6 & 846.9 & 783.8 \\
\hline & PSM & 823.8 & 867.5 & 837.3 & 782.1 \\
\hline & ERA-interim & 723.8 & 751.3 & 741.1 & 720.8 \\
\hline
\end{tabular}




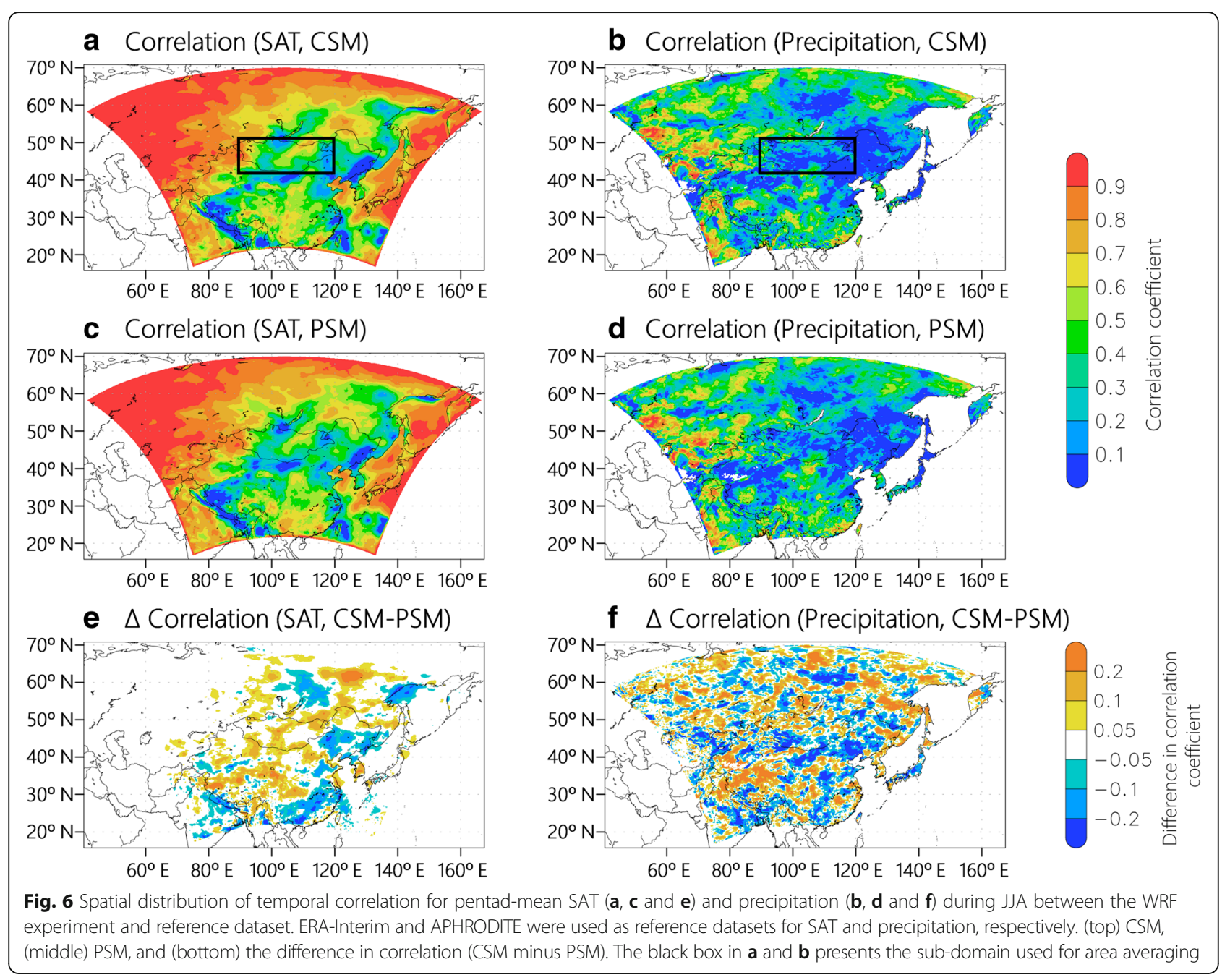

The correlation of precipitation is also analyzed at each grid point in Fig. $6 b, d$, and $f$. In both experiments, however, the correlation for pentad mean precipitation time series between APHRODITE and WRF is low $\left(R_{\mathrm{CSM}}=\right.$ 0.24 and $R_{\mathrm{PSM}}=0.17$ over the study domain). There is no significant difference in area-averaged (black box in Fig. 6b) daily precipitation between CSM and PSM during JJA (Student's $t$ test, 95\% confidence level). This unclear response of precipitation to SM indicates that the influence of SM on precipitation is complicated in space and time or that the expected impact is weak. Since the current study focused on high-temperature events in which the atmosphere is stable under high pressure and hence precipitation is low, additional analysis of years with more precipitation events is needed to understand the possible influences of SM on precipitation.

We have examined the performance of the CSM and PSM experiments against observations and reanalysis. In the following part of this study, further analysis was used to clarify the SM-atmosphere interaction, focusing on the SM difference between the CSM and PSM experiments.
The difference in SM between the CSM and PSM is inhomogeneously distributed (Fig. 7). It also varies on a subseasonal timescale, especially during the first and third HWs (Fig. 7b, d) over Mongolia by about $0.03 \mathrm{~m}^{3} \mathrm{~m}^{-3}$. In contrast, the area-averaged (black box in Fig. 7a) SM difference is small $\left(0.02 \mathrm{~m}^{3} \mathrm{~m}^{-3}\right)$ for the second HW (Fig. 7c). The horizontal distribution of anomalous latent and sensible heat flux is consistent with that of the anomalous SM (not shown), with more latent heat (less sensible heat) flux as SM increases. We will later discuss the SM's impact on middle tropospheric circulation through a comparison with SM patterns in Fig. 7.

Figure 8 depicts the difference in $500 \mathrm{hPa}$ geopotential height fields between the CSM and the PSM. The mean JJA geopotential field at $500 \mathrm{hPa}$ has a weak ridge over Mongolia. The strength of the ridge varies for each HW, and the strongest ridge occurred in the second HW. In the JJA mean field, the difference in geopotential height between the CSM and PSM was small (Fig. 8a). The greater differences occurred for the first (Fig. 8b) HW events in regions with lower SM in the CSM experiment 
a SM difference (CSM-PSM), JJA

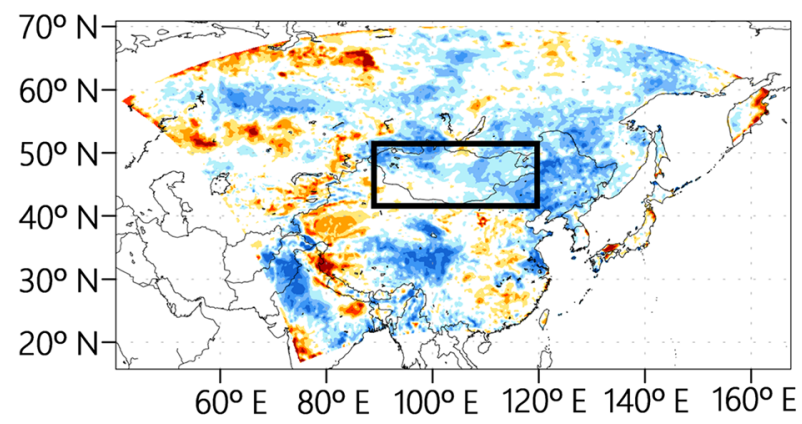

c SM difference (CSM-PSM), 2nd HW

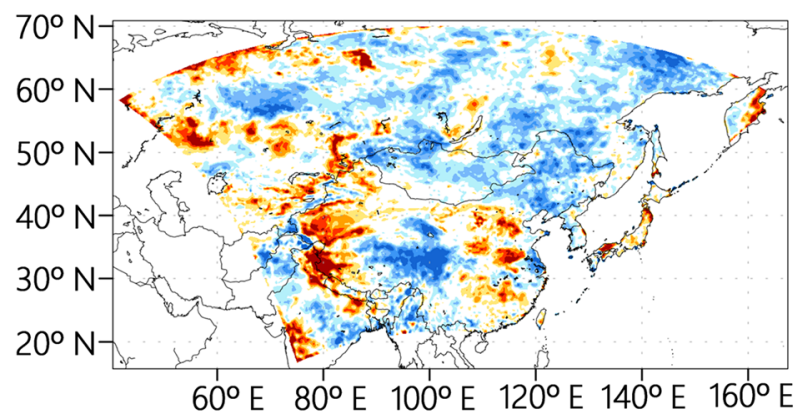

b SM difference (CSM-PSM), 1st HW

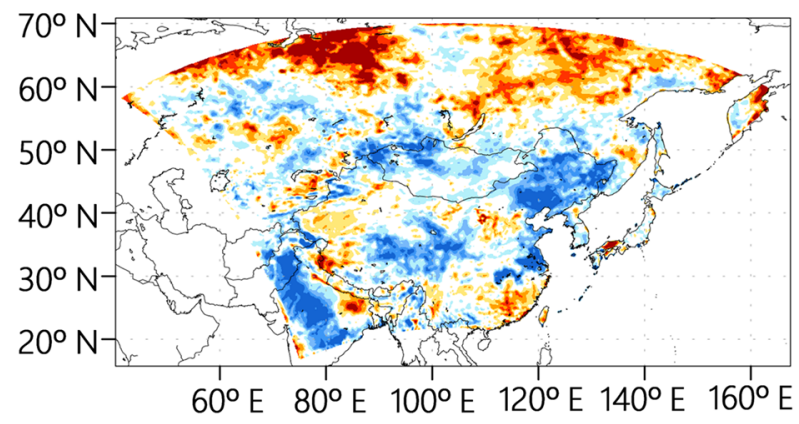

d SM difference (CSM-PSM), 3rd HW

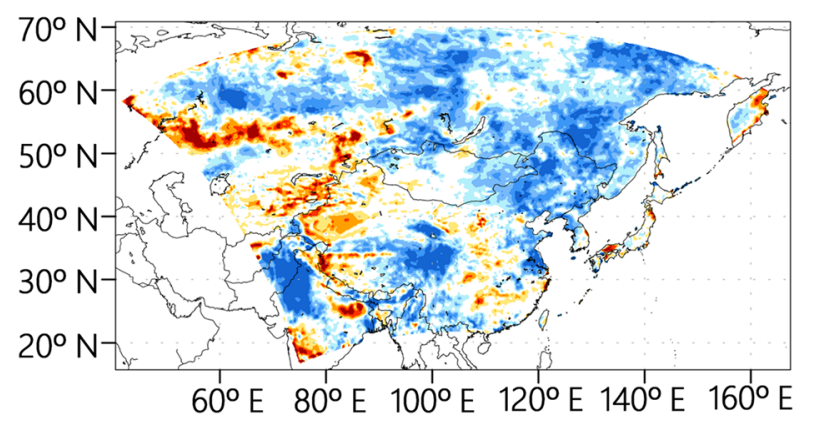

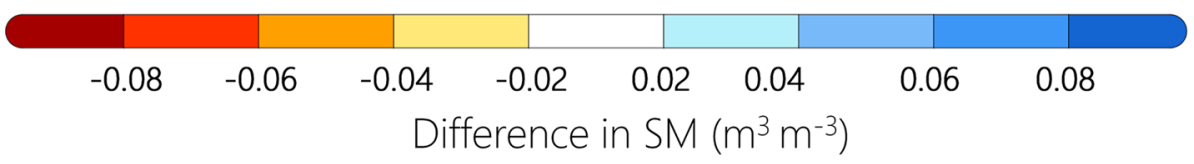

Fig. 7 Horizontal distribution of SM difference between the CSM and PSM experiments for a JJA, b first HW (25 June to 10 July), c second HW (16 July to 2 August), and $\mathbf{d}$ third HW (7 August to 27 August). The black box in a presents the sub-domain used for area averaging

(Fig. 7b). The atmospheric response to SM is strong in the first and second HW events, in which the $500 \mathrm{hPa}$ geopotential height increased by more than $25 \mathrm{~m}$ (Fig. 8b) and $20 \mathrm{~m}$ (Fig. 8c) in the PSM relative to the CSM experiment. On the other hand, the influence of SM to the middle troposphere tends to be weak in the third HW (Fig. 8d) when SM is much wetter in the CSM (Fig. 7d). This suggests that the impact of SM on the mid-tropospheric circulation differs among three HW events. Kanae et al. (2001) suggested that the impact of land surface anomaly is likely to present during the period when prevailing wind weakens. To investigate the relationship between the environmental winds and impact of SM anomaly, upper-level wind speeds were compared among $\mathrm{HW}$ events. The areal mean (black box in Fig. 8a) daily wind speeds in the CSM at $500 \mathrm{hPa}$ were $6.2,7.9$, and $8.1 \mathrm{~m} \mathrm{~s}^{-1}$ for the first, second, and third HWs, respectively. Under the relatively strong westerly wind during the third HW event, the impact of the SM anomaly might propagate weakly upward. It is speculated that the mid-troposphere is more sensitive to a SM anomaly when Northeast Eurasia is covered by a strong ridge and weak westerly wind, and less sensitive when strong westerly wind dominates. Further studies that consider different environmental conditions will be needed to verify this speculation.

Here, we discuss the strength of the coupling between land and atmosphere. To investigate the spatial distribution of temperature and SM interaction in the model experiments, a coupling strength is estimated by using the output from the CSM and PSM experiments. We followed the methodology proposed by Seneviratne et al. (2006), which considers the standard deviation of temporal variability (hereinafter, coupling strength) of particular variables derived from the CSM and PSM experiments. In this study, coupling strength is estimated by $\left(\sigma_{\mathrm{CSM}}{ }^{2}-\sigma_{\mathrm{PSM}}{ }^{2}\right) /\left(\sigma_{\mathrm{CSM}}{ }^{2}\right)$ where $\sigma_{\mathrm{CSM}}$ and $\sigma_{\mathrm{PSM}}$ represent the standard deviations of daily SAT (1400 LT) or precipitation during JJA in the CSM and PSM outputs, respectively. The coupling strength for SAT is highest in Siberia and east China (Fig. 9a). Positive coupling strength implies that SAT variability in the CSM experiment is larger than in the PSM experiment. The spatiotemporal distribution of the coupling strength for all JJA is not uniform. A high coupling strength is widely distributed over Siberia during the first 
a Z500hPa difference (CSM-PSM), JJA

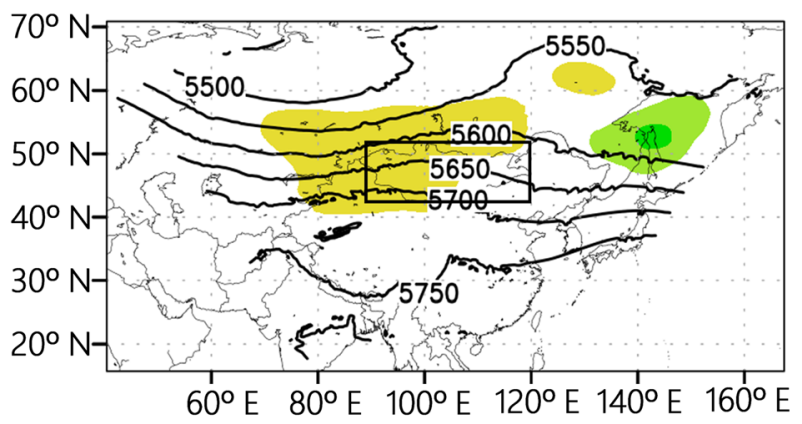

c Z500hPa difference (CSM-PSM), 2nd HW

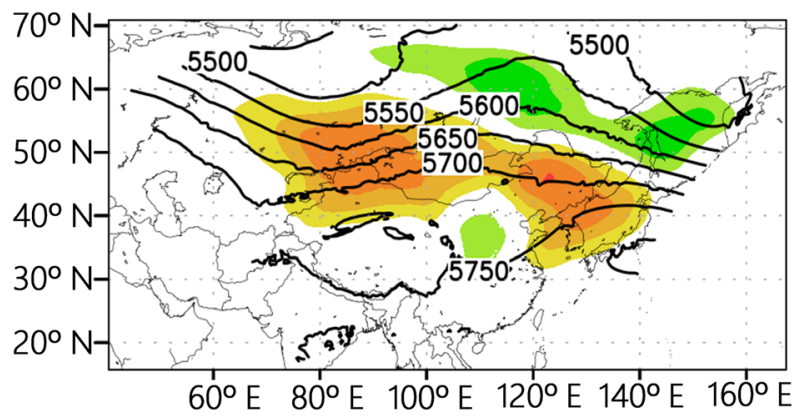

b Z500hPa difference (CSM-PSM), 1st HW

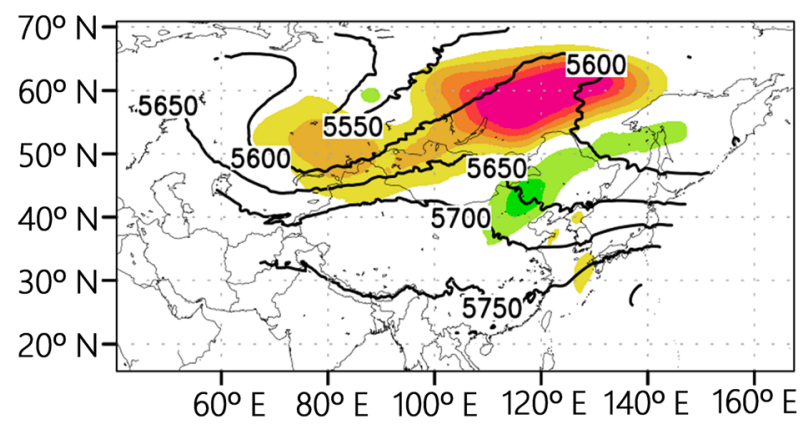

d Z500hPa difference (CSM-PSM), 3rd HW

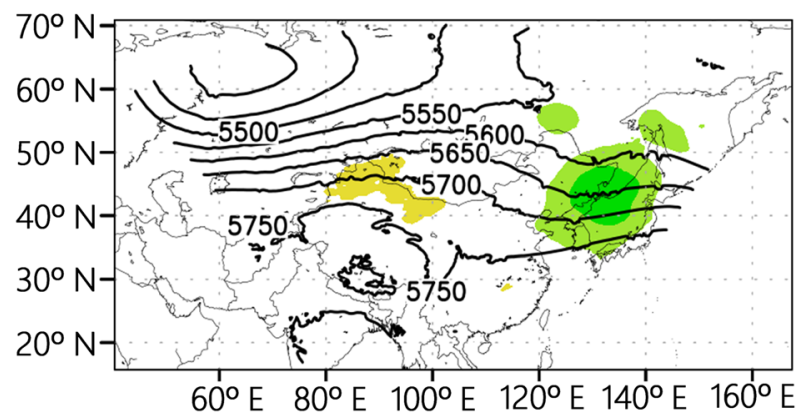

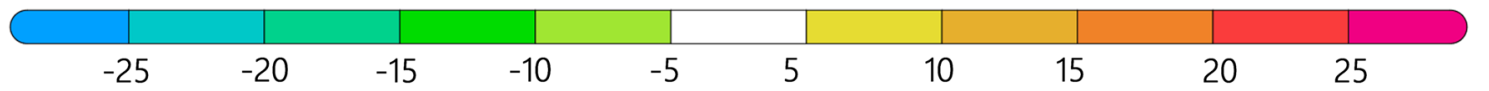

Difference in geopotential height (m)

Fig. 8 a-d Same as Fig. 7, but for 500 hPa geopotential height (Z500hPa) difference (shading). Contours represent 500 hPa geopotential height in the CSM experiment

HW event (Fig. 9b), which remains in JJA average (Fig. 9a). Since low SM (Fig. 7b) and high geopotential (Fig. 8b) are co-locating over Siberia in the CSM run, it is speculated that positive feedback in local land-atmosphere interaction is intensified during the first HW event. The area-averaged (black box in Fig. 9a) monthly based coupling strengths are 0.02, 0.17, and 0.04 for June, July, and August, respectively. The coupling strength during the first HW is high in the western Mongolia, which is likely to be caused by temperature advection rather than local SM-SAT coupling. A weaker surface westerly in the CSM results in weaker cold advection in the western Mongolia during the decaying period of first HW, leading to higher SAT variance in the CSM (Fig. 5b). The highest coupling strength appears in central China around the Yellow River basin during the third HW (0.68), suggesting that the impact of SM on SAT is strongest in this region (Fig. 9d). A negative coupling strength, namely higher variance of SAT in the PSM than the CSM, occurs when the availability of SM in the PSM is lower than in the CSM. In general, the coupling strength between SM and SAT was found to be low over the Mongolia. Here, we raise two possible reasons. Firstly, the sign of SM difference between CSM and PSM varies spatiotemporally. This allows the SAT difference being both positive and negative signs, and consequently, the difference in SAT variance between two runs becomes small, leading to low coupling strength. Secondly, the study domain covers various hydrological regimes from dry to humid regions, which may result in diverse atmospheric response against SM anomaly as indicated by Guo and Dirmeyer (2013).

The coupling strength for precipitation does not show meaningful signals in the studied area (Fig. 10). This result is consistent with other studies (Koster et al. 2004; Seneviratne et al. 2010; Zhang et al. 2011), which found weak coupling strength for SM and precipitation in multiple GCM experiments in this region. Guo and Dirmeyer (2013) found strong SM-to-precipitation coupling dominates over Northeast Asia in dry years. Since the targeting year was dry in our studied area, we expected a strong coupling in the current study. Although positive coupling strength in eastern Mongolia (Fig. 10a) agrees with Guo and Dirmeyer (2013), the coupling strength over the surrounding region seems to be randomly distributed. This 
a Coupling strength (SAT), JJA

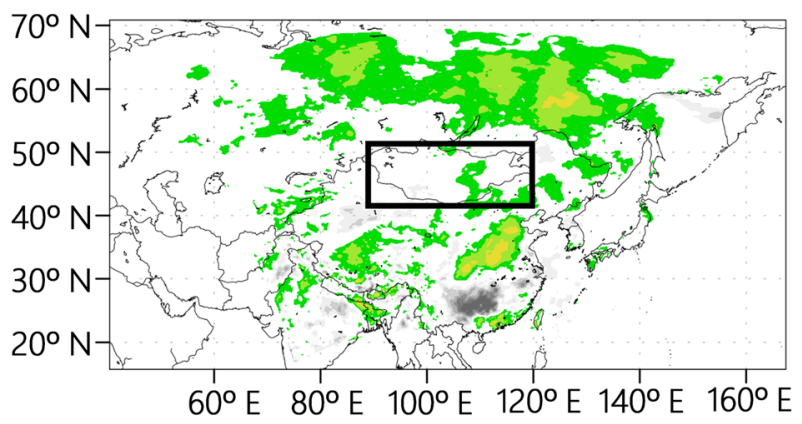

c Coupling strength (SAT), 2nd HW

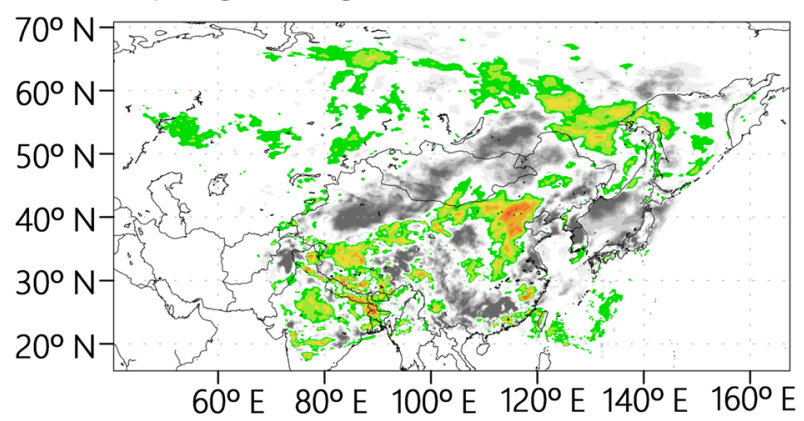

b Coupling strength (SAT), 1st HW

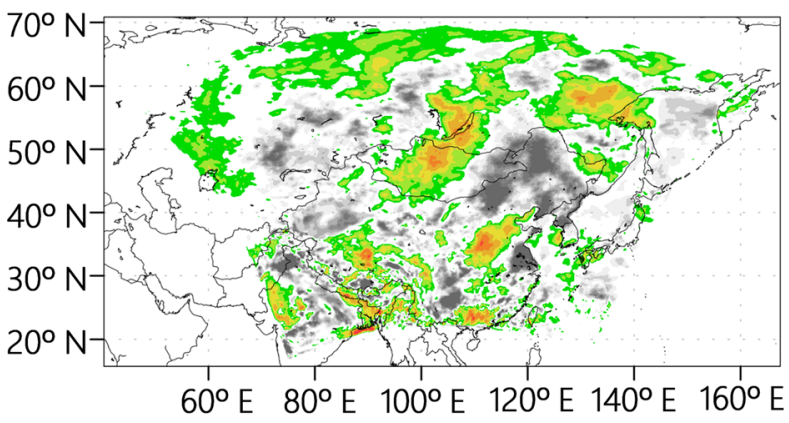

d Coupling strength (SAT), 3rd HW

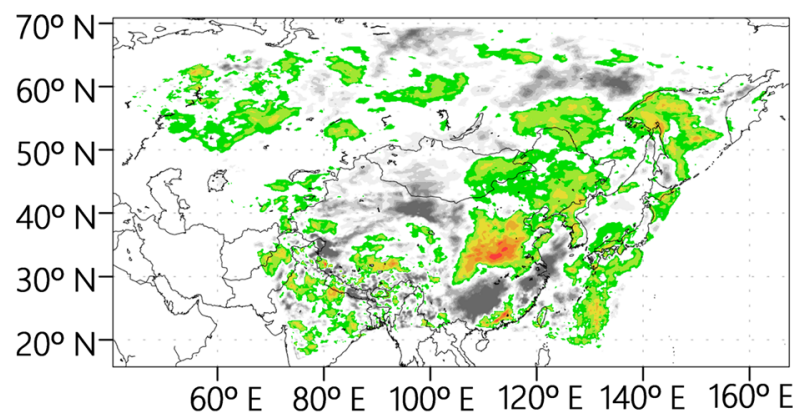

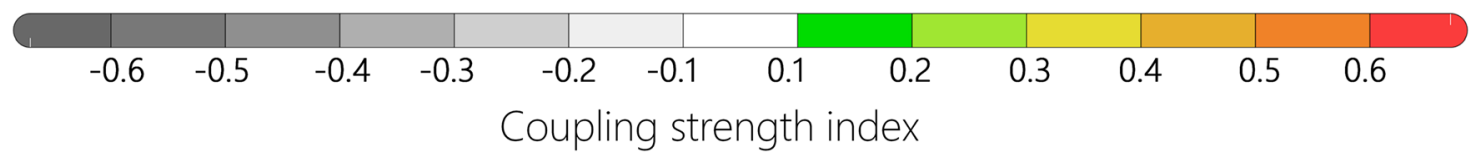

Fig. 9 Horizontal distribution of coupling strength for SAT for a JJA, b first HW (25 June to 10 July), c second HW (16 July to 2 August), and d third HW (7 August to 27 August)

may be due to different analysis period and different physics schemes in the model. Since this study is limited for typical hot summer in 2002, further investigation is needed by taking account of large number of cases for the analysis of SM-to-precipitation coupling.

\section{Conclusions}

In this study, the role of SM in the intensification of HW events in Northeast Eurasia has been investigated with observational datasets and numerical experiments for the extremely hot summer of 2002. A mid-tropospheric circulation analysis using the ERA-Interim reanalysis shows that HWs over Northeast Eurasia were triggered by mid-latitude wave trains. The Hovmöller diagram for SAT (Fig. 4b) demonstrates that HWs are concentrated around Mongolia associated with a low SM anomaly that can potentially enhance sensible heat flux and the mid-tropospheric ridge. Numerical experiments with (CSM) and without (PSM) SM-atmosphere interaction were conducted to study the importance of land-atmosphere interaction during the strong HW events in 2002. The correlations of pentad SAT and precipitation are high in
Northeast Eurasia and become lower toward the southeast of the study domain, suggesting that the contribution of SM to SAT is stronger in Northeast Eurasia. Dry (wet) SM conditions in the PSM experiment increase (decrease) SAT by enhancing (limiting) the sensible heat flux in comparison with the CSM experiment. The dry (wet) SM in the CSM experiment can intensify (weaken) the positive anomaly at $500 \mathrm{hPa}$ geopotential height. The coupling strength index reveals that there is higher coupling strength in Northeast Eurasia in this study domain and that land-atmosphere interaction varies on a sub-seasonal timescale. The CSM experiment resembles the variation in SAT seen in the reanalysis more closely than does the PSM, suggesting that land-atmosphere interaction is important in this region. On the other hand, in the PSM experiment, the model performance in simulating the temporal variation in SAT is better than the CSM over the east coast of China. Thus, correction of SM variation in the model using the satellite-based SM dataset has the potential to improve the sub-seasonal variability in SAT by constraining the internal variability in atmospheric circulation through land-atmosphere interaction. The correct 
a Coupling strength (Precipitation), JJA

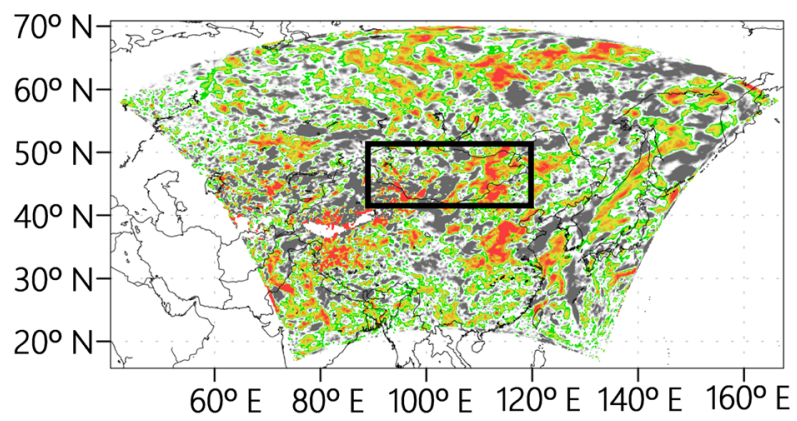

c Coupling strength (Precipitation), 2nd HW

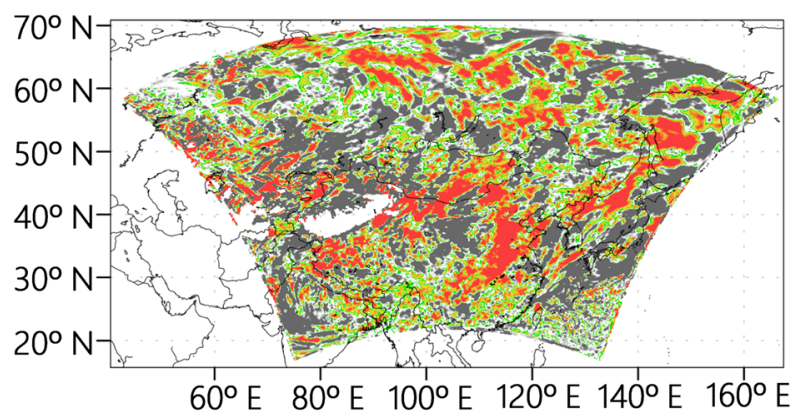

b Coupling strength (Precipitation), 1st HW

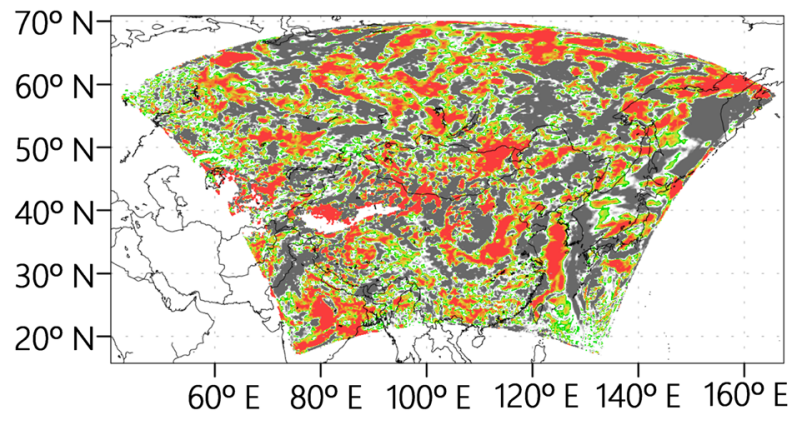

d Coupling strength (Precipitation), 3rd HW

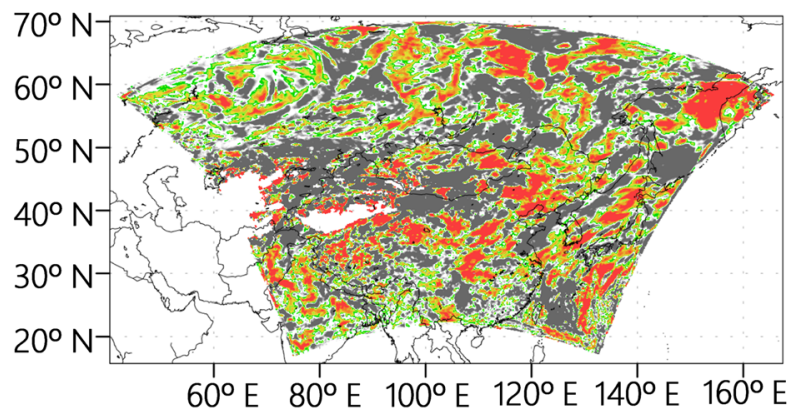

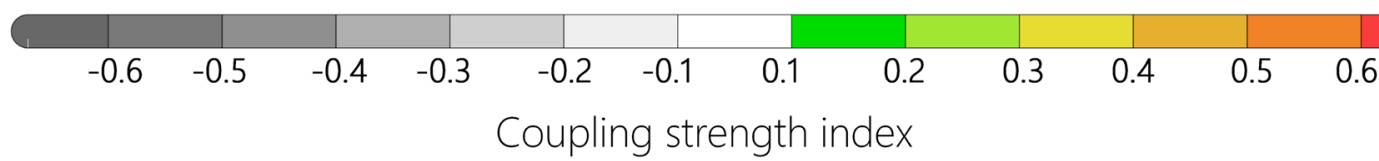

Fig. 10 a-d Same as Fig. 9 but for precipitation

land-atmosphere coupling in a model is expected to regulate the relationship between SM and SAT. The intensity of SM-atmosphere interaction varies spatially and temporally, i.e., there is weak interaction under strong westerly wind (during the third HW) and strong interaction under weak westerlies in the mid-troposphere, as occurred in summer 2002 over Northeast Eurasia. The CSM and PSM experiments suggest the importance of SM in regulating SM-atmosphere coupling that should eventually improve the representation of subseasonal variability in SAT during HW events.

Finally, we must point out the limitations of this study. In comparison to SM-SAT coupling, the SM-precipitation coupling strength is heterogeneously distributed. Although this might represent a complicated nonlinear interaction between SM and precipitation in mid-latitude, five ensemble experiments in this study may be too few to detect SM's impact on precipitation. A comprehensive analysis by using a large number of ensemble experiment is demanded in the future study. The SM dataset for the prescribed SM experiment also requires improvements. Recently, satellite-based and model-based SM products become available for such a purpose. However, there is a gap in seasonal mean SM values between the SM products and SM derived from atmospheric reanalysis. In such a case, simulated hydrological cycle in a regional climate model is likely to be biased that may hinder a proper evaluation of SM-precipitation interaction. With respect to future climate change, summer precipitation change around the studied region yet contains large uncertainty (Collins et al. 2013). Since SM-atmosphere interaction plays a key role in attributing the future change in summer precipitation (Sato et al. 2007), further studies are needed to enhance our understanding in land-atmosphere interactions over Northeast Eurasia.

\section{Abbreviations}

APHRODITE: Asian Precipitation Highly Resolved Observational Data Integration Towards Evaluation; ARW: Advanced Research WRF;

CSM: Coupled soil moisture; ECMWF: European Centre for Medium-range Weather Forecasts; ERA: ECMWF reanalysis; ESA-CCI: European Space AgencyClimate Change Initiative; HW: Heat wave; JJA: June-July-August; LSM: Landsurface model; LT: Local time; PSM: Prescribed soil moisture; RMSE: Root mean square error; SAT: Surface air temperature; SM: Soil moisture; UTC: Coordinated Universal Time; WRF: Weather Research and Forecasting: Z500hPa: Geopotential height at 500 hectopascal 


\section{Acknowledgements}

The authors acknowledge the Arctic Challenge for Sustainability Project and the Social Implementation Program on Climate Change Adaptation Technology (SI-CAT) project funded by the Ministry of Education, Culture, Sports, Science and Technology (MEXT) of Japan, and Grant-in-Aid for Young Scientists A (Grant No. 15H05464) funded by the Japan Society for the Promotion of Sciences (JSPS). The authors also would like to thank the two anonymous reviewers for their comments and suggestions to improve the quality of the paper.

\section{Funding}

This study was funded by the Arctic Challenge for Sustainability (ArCS) Project and Social Implementation Program on Climate Change Adaptation Technology (SI-CAT) by MEXT, Japan, and also the Grant-in-Aid for Young Scientists A (Grant No. 15H05464) by the Japan Society for the Promotion of Sciences (JSPS).

\section{Availability of data and materials}

The datasets used, generated, and analyzed during the current study are available from the corresponding author on reasonable request.

\section{Authors' contributions}

EE and TS proposed the topic. EE conceived the study and analyzed the data. TS designed the experiment and interpreted the results of the experiment. EE wrote the first draft, and TS revised the manuscript. Both authors read and approved the final manuscript.

\section{Competing interests}

The authors declare that they have no competing interests.

\section{Publisher's Note}

Springer Nature remains neutral with regard to jurisdictional claims in published maps and institutional affiliations.

Received: 10 July 2017 Accepted: 6 July 2018

Published online: 27 July 2018

\section{References}

Alexander LV, Zhang X, Peterson TC, Caesar J, Gleason B, Klein Tank AM, Haylock M, Collins D, Trewin B, Rahimzadeh F, Tagipour A (2006) Global observed changes in daily climate extremes of temperature and precipitation. J Geophys Res 111:05109. https://doi.org/10.1029/2005JD006290

Beniston M (2004) The 2003 heat wave in Europe: a shape of things to come? An analysis based on Swiss climatological data and model simulations. Geophys Res Lett 31:02202. https://doi.org/10.1029/2003GL018857

Berg A, Lintner BR, Findell K, Seneviratne SI, van den Hurk B, Ducharne A, Chéruy F, Hagemann S, Lawrence DM, Malyshev S, Meier A (2015) Interannual coupling between summertime surface temperature and precipitation over land: processes and implications for climate change. J Clim:1308-1328. https://doi.org/10.1175/JCLI-D-14-00324.1

Black E, Blackburn M, Harrison G, Hoskins B, Methven J (2004) Factors contributing to the summer 2003 European heatwave. Weather 59:217-223. https://doi.org/10.1256/wea.74.04

Collins M, Knutti R, Arblaster J, Dufresne JL, Fichefet T, Friedlingstein P, Gao X, Gutowski WJ, Johns T, Krinner G, Shongwe M, Tebaldi C, Weaver AJ, Wehner M (2013) Long-term climate change: projections, commitments and irreversibility. In: Stocker TF, Qin D, Plattner G-K, Tignor M, Allen SK, Boschung J, Nauels A, Xia Y, Bex V, Midgley PM (eds) Climate Change 2013: The Physical Science Basis. Contribution of Working Group I to the Fifth Assessment Report of the Intergovernmental Panel on Climate Change. Cambridge University Press, Cambridge, United Kingdom and New York, NY, USA

Dee DP, Uppala SM, Simmons AJ, Berrisford P, Poli P, Kobayashi S, Andrae U, Balmaseda MA, Balsamo G, Bauer P, Bechtold P (2011) The ERA-interim reanalysis: configuration and performance of the data assimilation system. Q J R Meteorol Soc 137:553-597. https://doi.org/10.1002/qj.828

Della-Marta PM, Haylock MR, Luterbacher J, Wanner H (2007) Doubled length of western European summer heat waves since 1880. J Geophys Res 112:15103. https://doi.org/10.1029/2007JD008510
Dole R, Hoerling M, Perlwitz J, Eischeid J, Pegion P, Zhang T, Quan XW, Xu T, Murray D (2011) Was there a basis for anticipating the 2010 Russian heat wave? Geophys Res Lett 38:06702. https://doi.org/10.1029/2010GL046582

Dudhia J (1989) Numerical study of convection observed during the winter monsoon experiment using a mesoscale two-dimensional model. J Atmos Sci 46:3077-3107. doi: https://doi.org/10.1175/1520-0469(1989)046<3077: NSOCOD>2.0.CO;2

Ek MB, Mitchell KE, Lin Y, Rogers E, Grunmann P, Koren V, Gayno G, Tarpley JD (2003) Implementation of Noah land surface model advances in the National Centers for Environmental Prediction operational mesoscale Eta model. J Geophys Res 108:8851. https://doi.org/10.1029/2002JD003296

Erdenebat E, Sato T (2016) Recent increase in heat wave frequency around Mongolia: role of atmospheric forcing and possible influence of soil moisture deficit. Atmos Sci Lett 17:135-140. https://doi.org/10.1002/asl.616

Ferranti L, Viterbo P (2006) The European summer of 2003: sensitivity to soil water initial conditions. J Clim 19:3659-3680. https://doi.org/10.1175/ JCLI3810.1

Fischer EM, Seneviratne SI, Vidale PL, Lüthi D, Schär C (2007) Soil moistureatmosphere interactions during the 2003 European summer heat wave. J Clim 20:5081-5099. https://doi.org/10.1175/JCLI4288.1

Gross MH, Donat MG, Alexander LV, Sisson SA (2017) The sensitivity of daily temperature variability and extremes to dataset choice. J Clim 31:1337-1359. https://doi.org/10.1175/JCLI-D-17-0243.1

Guo Z, Dirmeyer PA (2013) Interannual variability of land-atmosphere coupling strength. J Hydrometeorol 14:1636-1646. https://doi.org/10.1175/JHM-D-12-0171.1

Hartmann DL, Tank AM, Rusticucci M, Alexander LV, Brönnimann S, Charabi YA, Dentener FJ, Dlugokencky EJ, Easterling DR, Kaplan A, Soden BJ (2013) Observations: atmosphere and surface. In: Climate change 2013 the physical science basis: Working Group I Contribution to the Fifth Assessment Report of the Intergovernmental Panel on Climate Change 2013 Jan 1. Cambridge University Press. https://doi.org/10.1017/CBO9781107415324.008

Kain JS (2004) The Kain-Fritsch convective parameterization: an update. J Appl Meteorol 43:170-181. https://doi.org/10.1175/1520-0450(2004)043<0170: TKCPAU > 2.0.CO;2

Kanae S, Oki T, Musiake K (2001) Impact of deforestation on regional precipitation over the Indochina Peninsula. J Hydrometeorol 2:51-70. https://doi.org/10, 1175/1525-7541(2001)002<0051:IODORP>2.0.CO;2

Koster RD, Chang Y, Schubert SD (2014) A mechanism for land-atmosphere feedback involving planetary wave structures. J Clim 27:9290-9301. https:// doi.org/10.1175/JCLI-D-14-00315.1

Koster RD, Dirmeyer PA, Guo Z, Bonan G, Chan E, Cox P, Gordon CT, Kanae S, Kowalczyk E, Lawrence D, Liu P (2004) Regions of strong coupling between soil moisture and precipitation. Science 305:1138-1140. https://doi.org/10. 1126/science.1100217

Lau N, Nath MJ (2012) A model study of heat waves over North America: meteorological aspects and projections for the twenty-first century. J Clim 25:4761-4784. https://doi.org/10.1175/JCLI-D-11-00575.1

Liu YY, Parinussa RM, Dorigo WA, De Jeu RA, Wagner W, Van Dijk Al, McCabe MF, Evans JP (2011) Developing an improved soil moisture dataset by blending passive and active microwave satellite-based retrievals. Hydrol Earth Syst Sci 15:425. https://doi.org/10.5194/hess-15-425-2011

Meehl GA, Tebaldi C (2004) More intense, more frequent, and longer lasting heat waves in the 21st century. Science 305:994-997. https://doi.org/10.1126/ science.1098704

Mlawer EJ, Taubman SJ, Brown PD, lacono MJ, Clough SA (1997) Radiative transfer for inhomogeneous atmospheres: RRTM, a validated correlated- $k$ model for the longwave. J Geophys Res 102:16663-16682. https://doi.org/10. 1029/97JD00237

Rogers E, Black T, Ferrier B, Lin Y, Parrish D, DiMego G (2001) Changes to the NCEP Meso Eta Analysis and Forecast System: increase in resolution, new cloud microphysics, modified precipitation assimilation, modified 3DVAR analysis. NWS Technical Procedures Bulletin 488:15

Sato T, Kimura F, Kitoh A (2007) Projection of global warming onto regional precipitation over Mongolia using a regional climate model. J Hydrol 333: 144-154. https://doi.org/10.1016/j.jhydrol.2006.07.023

Sato T, Xue Y (2013) Validating a regional climate model's downscaling ability for East Asian summer monsoonal interannual variability. Clim Dyn 41:24112426. https://doi.org/10.1007/s00382-012-1616-5

Schär C, Vidale PL, Lüthi D, Frei C, Häberli C, Liniger MA, Appenzeller C (2004) The role of increasing temperature variability in European summer heatwaves. Nature 427:332-336. https://doi.org/10.1038/nature02300 
Schubert SD, Wang H, Koster RD, Suarez MJ, Groisman PY (2014) Northern Eurasian heat waves and droughts. J Clim 27:3169-3207. https://doi.org/10. 1175/JCLI-D-13-00360.1

Seneviratne SI, Corti T, Davin EL, Hirschi M, Jaeger EB, Lehner I, Orlowsky B, Teuling AJ (2010) Investigating soil moisture-climate interactions in a changing climate: a review. Earth Sci Rev 99:125-161. https://doi.org/10.1016/ j.earscirev.2010.02.004

Seneviratne SI, Lüthi D, Litschi M, Schär C (2006) Land-atmosphere coupling and climate change in Europe. Nature 443:205-209. https://doi.org/10.1038/ nature05095

Seneviratne SI, Nicholls N, Easterling D, Goodess CM, Kanae S, Kossin J, Luo Y, Marengo J, Mclnnes K, Rahimi M, Reichstein M, Sorteberg A, Vera C, Zhang X (2012) Changes in climate extremes and their impacts on the natural physical environment. In: Field CB, Barros V, Stocker TF, Qin D, Dokken DJ, Ebi KL, Mastrandrea MD, Mach KJ, Plattner GK, Allen SK, Tignor M, Midgley PM (eds) Managing the risks of extreme events and disasters to advance climate change adaptation, A Special Report of Working Groups I and II of the Intergovernmental Panel on Climate Change (IPCC). Cambridge University Press, Cambridge, UK, and New York, NY, USA, pp 109-230

Skamarock WC, Klemp JB, Dudhia J, Gill DO, Barker DM, Wang W, Powers JG (2005) A description of the advanced research WRF version 2. NCAR Tech. Note NCAR/TN-468+STR 88.

Su H, Dickinson RE (2017) On the spatial gradient of soil moisture-precipitation feedback strength in the April 2011 drought in the southern Great Plains. J Clim 30:829-848. https://doi.org/10.1175/JCLI-D-13-00185.1

Weisheimer A, Doblas-Reyes FJ, Jung T, Palmer TN (2011) On the predictability of the extreme summer 2003 over Europe. Geophys Res Lett 38:05704. https:// doi.org/10.1029/2010GL046455

Yatagai A, Kamiguchi K, Arakawa O, Hamada A, Yasutomi N, Kitoh A (2012) APHRODITE: constructing a long-term daily gridded precipitation dataset for Asia based on a dense network of rain gauges. Bull Amer Meteor Soc 93: 1401-1415. https://doi.org/10.1175/BAMS-D-11-00122.1

Zaitchik BF, Macalady AK, Bonneau LR, Smith RB (2006) Europe's 2003 heat wave: a satellite view of impacts and land-atmosphere feedbacks. Int J Climatol 26 743-769. https://doi.org/10.1002/joc.1280

Zhang J, Wu L, Dong W (2011) Land-atmosphere coupling and summer climate variability over East Asia. J Geophys Res 116:05117. https://doi.org/10.1029/ 2010JD014714

\section{Submit your manuscript to a SpringerOpen ${ }^{\circ}$ journal and benefit from:}

- Convenient online submission

- Rigorous peer review

- Open access: articles freely available online

High visibility within the field

- Retaining the copyright to your article

Submit your next manuscript at $\boldsymbol{\nabla}$ springeropen.com 